\title{
Introduction: Society, regulation and governance: new modes of shaping social change?
}

\section{Regine Paul and Marc Mölders}

Since the origins of philosophical reflections, scholars have been busied with questions of how society can best be shaped and how, in turn, society itself shapes the very conditions and patterns of human interaction. Early treatises on "shaping society" include Aristotle's consideration of the benefits of communal life in a city state, Confucian ideas on how governments can best promote people's virtue for societal good, and Machiavelli's thoughts on the prerequisites of successful and powerful ruling. What unites these strands of thought is the belief in societal malleability, i.e. the possibility for intentional, that is, directed and directional "governmental" (in a broad sense) action aimed at making a difference in social developments.

While citizens have long puzzled over how society shapes their lives and how society can be shaped according to their ideals, state philosophers, political theorists and sociologists have not seemed to come to any final agreement (either within or across their respective disciplines) about how such shaping occurs, how predictable it can be, and what its exact outcomes are. "Society" presents itself as a classic moving target - today famously vexed with the complex and deeply unsettling dynamics that are summarized under the heading of globalization. Thus, theorizing about "shaping society" has produced countless claims about new instruments, new tools, new goals, new actors, new arenas and new procedures involved in such shaping processes. With such novelty claims and new analytical venues gaining momentum, there has been a tendency to bracket off questions of societal malleability and intentional change.

This volume takes up one line of such argumentation and reappraises the academic debate about new modes of regulation and governance. In doing so, it re-focuses on (the possibility of) intentional change in contemporary society. We argue that, in much of the literature concerned with novelty diagnoses, questions of social malleability have been moved back stage, yet they still pull essential conceptual and analytical strings there. 
The notion of shaping society serves as a bridging concept to acknowledge that regulation and governance research is marked by the co-existence of new modes of societal control and, at the same time, a rather unaltered (although often implicit) analytical attention to intentional social changes.

While new modes of regulation and governance might usefully clarify the role of hierarchical and formalized rule-making, they do not usually claim that state supported law and law-making have lost all relevance. Neither do they lose sight of what we will call "the essence" of regulation and governance: the attempt of intentionally changing society in some pre-established and specific way. Indeed, the fact that intended results may not be achieved often leads to new waves of revising existing regulatory and governance approaches, rather than giving up trying (e.g. illustrated in the discussion on how behaviors of regulatees can be best modified also without hierarchical law-making; cf. Hood et al. 2001). Underpinning our conceptual and empirical engagement throughout the chapters is a twofold understanding of regulation and governance. Regulation and governance are - at the same time - innovatively minded and, at their respective cores, concerned with how intentional social change can be fostered and what results it can wield in terms of shaping society. The prominence we give to the notion of intentional change in this edited volume's title pays tribute to our conceptual argument. Even though novelty and innovation claims guide much contemporary research on regulation and governance ${ }^{1}$ ("new modes of. .."), we should not too readily renounce the possibility that political interventions always had and potentially always will have intentions, target specific social changes and are continuously backed by, or at least embedded in, a wider set of legal rules and sanctions. Furthermore, they always wield specific societal effects, even if it is in ways that were not originally predicted or envisaged.

Rather than adding yet another theory about shaping society to the already crowded market, this volume pauses to take stock of the debate and critically assess novelty claims. We seek to engage with existing arguments by examining scholarly discussions in social sciences and legal studies on new modes of intentional change in regulation and governance research. What do novelty claims refer to in regulation and governance research? How has our conceptual language developed to take account of the supposed novelty? To what extent does law and formal rule-making by the state still matter in these debates? How has novelty played out in specific empirical examples of regulation and governance? To what extent have new modes of intentional change contributed to overcoming issues with more conventional forms of "ruling", "steering" and "governing"? And finally, what's really new about such novelty claims and how do they feature in wider historically embedded accounts of social sciences reason- 
ing and its repercussions in policy-making? To address this set of questions in a systematic manner, our critical assessment takes three distinct forms:

- a conceptual-analytical mapping of regulation and governance and their ability to account for modes of intentional change which can be observed in contemporary society (see chapters by Bora and Carmel);

- detailed empirical examinations of two specific "new" modes of intentional change which have received wide attention: risk (see chapters by Paul, Rothstein and Beaussier, and Huber) and publics (see chapters by Viellechner, Mölders, and Schrape); and last but not least

- a wider historicizing embedding of contemporary novelty claims, specifically with regard to "shaping society" in twentieth century discourses about "activated" or "engineered" forms of participation as they unfolded at the science-policy interface (see chapters by Kuchenbuch and Münte).

It is with this mix of conceptual appraisal, empirical case studies, and a wider historicizing contextualization - and by including contributions by an interdisciplinary set of scholars from sociology, political sciences, legal studies and contemporary history - that we hope to contribute to more reflexivity on our own scholarly assumptions about what novelty may be about and where we observe continuity in the debates about regulation and governance.

While the structure of the book's chapters follows the three sections outlined above, the contributions speak to one another across sections. As we indicate next, they address several of the core conceptual ingredients which we identify as significant for understanding and assessing new modes of intentional change in regulation and governance. Rather than detailing individual contributions, our introduction will now substantiate three general observations about major division lines as well as potentially shared ground in the academic debate about "shaping society" and indicate how the volume's chapters relate to these. These observations consider academic debates about (a) the objects of intentional change, (b) the effects of attempts of intentional change and (c) the best conceptual means of capturing processes of intentional change. Jointly, they nourish our volume's chief premise that it is analytically useful to identify (and refocus on) a common core in the seemingly divergent conceptual approaches of regulation and governance. We thus map out what we call "the essence" of regulation and governance - intentional modes of social change - and 
thereby develop a compass for the volume and the principal lenses of its contributions.

Talk about "shaping society" first and foremost refers to the relationship between modes of intentional change and the object of such change. There has been wide discussion in the social sciences about the degree to which society as such can be the object of any intentional change in the first place. The so-called "crisis of interventionist thinking" was fostered by the experience that modern conditions render accurate and intended social change impossible - at least not without accepting unintended side-effects (see chapter by Bora). This connects to the wider claim that, given the "complexity" of modern society, any attempt to intentionally influence societal developments has to take into account that their object is not isolated, but forms part of a "turbulent world" in which the complex interplay of different social spheres, institutions, arenas of decision-making, norms, values, standards, operational criteria, etc., makes governing difficult (as prominently argued in complexity theory, e.g. Room 2011; also: Benz 2004). Indeed, it is now common sense that regulation and governance might be "often achieved in rather unexpected and contingent ways" (see chapter by Carmel).

This points to the ambivalent diagnosis that while scientific knowledge about the issues with intentional change is flourishing, we simultaneously witness an ever-increasing range of new instruments (such as risk analysis), new forums (such as publics) and new procedures (such as participation and consultation) which are deemed more suitable to shape society. Thus, from our viewpoint, "shaping society" is strongly connected to both a scholarly and a practice-related reluctance to give up on the evolution of tools, methods, procedures, etc., which are designed to (better) foster change. This is probably clearest in the empirical case analyzed by Kuchenbuch. Even though the possibility of intentional social change is restricted and troubled at best, losing sight of society (or at least relevant parts thereof) as an object of intentional change is not considered an option either. In other words, the intention to change outlives its own failure to induce accurate social change. Indeed, the debate about reflexive law epitomizes the idea that, in order to continuously impact societal developments, law needs to be reflexive; it needs to build the possibility of failing to reach its aims and an adaptation mechanism for such failures into its DNA (Teubner and Willke 1984; Teubner 2013). With the resilience of intentional change, the state and its formal rule-making have survived, too, despite the widely acknowledged limitations and despite repeated attempts to write them off or to at least ascribe to them with diminished relevance (see chapter by Bora).

This ambivalence connects to our second observation on the effects of 
shaping. The survival of often ill-fated intentions to foster social change points to the fact that what seems to be taken for granted in processes of regulation and governance, namely "society" - or at least sub-sections of society as a target for intentional change - is of course itself always evolving. For instance, changing modes of coordinating higher education (see chapter by Huber) or the attempt to find workable transnational arrangements for dealing with property rights on the Internet (see chapter by Viellechner) have almost automatically raised novel economic, political, scientific and legal questions. Such evolutionary dynamics prevail even where interventions fail to change societal interactions as intended. Because any attempt at intentional change must be seen in the light of its actual societal consequences, to us "shaping society" also - and maybe especially - makes sense if change occurs along unintended lines. Our conceptual assessment of the regulation and governance debate therefore considers their ability to offer "systematic explanations of the wider consequences of governing processes" regardless of whether such governing ever actually meets its aims (Carmel, in this volume, refers to this task as "governance analysis"; cf. Carmel forthcoming). This prominently includes analyses of the ambiguous positions of some new actors of governance between co-regulator, self-regulator and regulatee (see chapter by Schrape).

Our third observation concerns the conceptual means of capturing "shaping society" and the new modes by which such shaping occurs. In coming to terms with the ambivalence of intentional social change, simultaneously ill-fated and resilient attempts (our first observation), and the consequences of attempts of intentional change even where they fail (our second observation), social scientists have seemingly taken two different routes in their development of concepts and analytical frameworks (see chapters by Bora, Carmel, and Paul). As such, the co-existence of regulation and governance as analytical concepts must be interpreted, at least in part, as a scholarly reaction to the proliferation of modes and forms of shaping society. Yet, such bifurcation has been questioned regarding the clarity of its analytical language and foci, and even its ability to explain contemporary processes of shaping society (e.g., Blumenthal 2005; Bora 2014; Döhler and Wegrich 2010; Sack 2013). Rather than "taking sides" in a paradigmatic battle, and rather than adding yet another theory of shaping society, we consider it analytically useful to identify a common core in the seemingly divergent conceptual approaches of regulation and governance. Doing so would help us refocus analytical attention on the essence of what shaping society is about - namely, intentional social change, and to look past the potential value inflation and deflation of academic and reform-political concepts.

We do not offer any further detail on the evolution of social-scientific 
paradigms here, as this will be the task of the volume's conceptual contributions. However, more generally speaking, the scholarly diagnosis of an expansion of the levels, actors and modes of social control as a response to the felt inability of traditional approaches to foster desired kinds of change has informed a perceived need for a new conceptual language in the social sciences, one that would be better able to capture changing empirical realities (see chapters by Carmel and Münte). During recent decades, the academic debate has considerably shifted its attention away from regulation and toward the concept of governance (e.g. Bevir 2013; Bevir and Rhodes 2010; Mayntz and Scharpf 1995; Pierre 2000; Pierre and Peters 2000; Rhodes 1996). A recent handbook even subsumes public law and regulation as one theoretical foundation of governance among several others (Ansell and Torfing 2016). Criticizing evident flaws of the often narrow instrumental, state-centric and law-focused "command and control" concept of regulation, governance gained importance in the social sciences and political debates as a concept which sought to overcome such shortcomings by accounting for innovative modes of "governance without government" (Rhodes 1996). The concept also aimed to account more adequately for new socially relevant phenomena of coordination to cope with complexity and interdependencies (e.g. Benz et al. 2007b; Jansen 2010; Mayntz 2006). The very proliferation of claims of empirical novelty with regard to how society is shaping and being shaped has hence cumulated in a new paradigm. At the same time, however, regulation concepts have been "updated" with adjectives such as "responsive", "smart", "reflexive", "better" or "meta" regulation, which have gained substantial influence (see chapters by Bora and Huber). This conceptual expansion has come in response to the perception that a narrow concept of regulation - conventionally understood as "sanctionable enforcement of statutory rules" (Döhler and Wegrich 2010: 34, translation from German) - no longer fully captures the empirical reality of new modes of intentional change.

However, there are many potential flaws and unintended effects of "shaping society". We may discuss modes of influencing social change in a specific direction, but also modes of coping with unintended effects of such interventions. These have been recurring themes, and not just in revised theories of regulation. Governance has certainly expanded the analytical view beyond the usual suspects of intentional change, i.e. the state, its formal rules and sanctioning power. Yet, at its very heart, governance is still concerned with notions of "capacity, authority, sovereignty and autonomy", which all relate to ideas of influence and scope. Even though governance narratives claim that these features have become "uncertain, unpredictable, and variable across policy dimensions" as well as highly 
dispersed across actors and arenas of public decision-making, they do not question their fundamental relevance in shaping patterns of influence (see chapter by Carmel; also that by Viellechner). Scholars may disagree about the extent to which such patterns may have become more complex, as the role of the state and its legal rule-making is now considerably flanked by that of other actors and forms of wielding influence. Yet behind the specificities of each approach there remains a common interest of both regulation and governance in the exertion of influence over social change. In our terminology, they both focus on the fostering of intentional social change under ever-changing and highly unpredictable environmental conditions. What bridges the paradigms in the social sciences, in other words, is a largely affirmative discourse about the malleability of society.

If the engagement with intentional social change in a principally malleable society constitutes the essence of regulation and governance, novelty claims in the scientific debate have to be considered as being not so much concerned with whether or not society can be shaped, but with the specific modes through which such change occurs. To detail our generic observations and conceptual arguments above and specify the conceptual appraisal offered briefly in this introduction and substantiated in the volume's first two contributions (see chapters by Bora and Carmel), we examine two new modes of intentional change empirically in more depth across six contributions.

Our first case considers risk. This is an analytical focus that features prominently in both paradigms, with the respective studies now easily filling entire book shelves in university libraries. By systematically comparing relevant literature of both stances (see chapter by Paul), considerable commonalities and differences of how regulation and governance approaches conceptualize risk can be identified and explained. Risk is inherently associated with novelty: either risks themselves are regarded as constantly changing (as the policy-relevant and academic discussions about "newly emerging risks" highlight) and requiring regulatory reactions or the tools and processes by which risks are to be analyzed and managed are considered to require innovation where they fail to lead to intended effects; risk itself is also identified as a novel regulatory heuristic by which interventions can be rationalized.

Indeed, frustrations about the inability to fully predict and control societal risk - either through classic instrumental regulation or via broader participatory governance arrangements - have yielded a "reflexive turn" in social science discourses on risk. In this context, risk-based regulation (see chapters by Huber, and Rothstein and Beaussier) counts, on the one hand, as a novel regulatory practice for facilitating intentional change despite the "limits of governance" when facing complex risk problems (Rothstein et 
al. 2013). On the other hand, it features as a novel and decidedly reflexive tool for observing failure-prone attempts of intentional change (Rothstein 2006). By rationalizing the limits of one's own ability to exert influence over risks upfront, the political effects of failing to prevent all societal risks can at least be cushioned as responsibility is re-allocated across regulators, regulatees and risk bearers. Risk-based regulation is inherently occupied with the possibility of "taming" uncertainty and making complex and uncertain futures more predictable and manageable by risk analysis. This occurs all while acknowledging that unforeseen events will occur and that not all adverse outcomes can be avoided. In that sense, risk-based regulation epitomizes this volume's argument that novelty claims in regulation and governance research are united by an inherent acknowledgment of both the intentionality of respective interventions and the unavoidability of unintended effects.

Comparative work on the uneven cross-national adoption of risk-based regulation serves as a prime example for this acknowledgment. Risk-based regulation counts as a universal strategy to deal with scarce resources and complex regulatory demands in a rational manner, which can raise the regulator's ability to shape societal outcomes intentionally (Baldwin et al. 2013a; Black 2005; Rothstein 2006; Rothstein et al. 2006). Alternatively, comparative work in particular points to the institutional and ideational limits as well as the unintended side effects of such seemingly rational interventions. This is the case in work safety regulation, where risk-based prioritization has emerged in several European countries as a joint response to common challenges. However, each country filters such prioritization in anticipation of their inability to shape society in ways that are incompatible with chief institutions, including prominently, the welfare state (see chapter by Rothstein and Beaussier; also see Paul and Huber 2015; Paul 2016). A similar dynamic unfolds in higher education regulation. As a response to the alleged failure of a self-regulatory system, where the ensuring of academic quality was largely a task for the profession itself, there has been a move toward tighter and often more hierarchically steered regulatory regimes throughout Europe since the 1990s. "Novelty" in this sector entailed a turn away from long-standing self-regulatory approaches toward a more classic involvement of states and state law. As malleability of the university sector is to be increased with quality regulation, the management of unintended effects has to a large degree already been built in to the regimes: responsiveness and reflexivity have become common traits of academic quality regulation. Yet what reflexivity means and what it targets in respective quality regulation regimes differ considerably between countries (see chapter by Huber). Overall then, comparative analyses of how a rather novel regulatory tool - risk-based regulation - is being adopted 
across countries indicate a lasting dedication to the century-old question of malleability, including a modern focus on the reflexive management of unintended consequences. Yet the case of risk also neatly demonstrates that what exactly is considered malleable and what becomes the target of intentional change varies greatly across institutional backgrounds and is based on diverse normative assumptions about what state interventions should be about.

Our second example addresses the role of the public sphere in shaping society. Discussions of novelty in the context of governance or regulation often refer to new players entering the field. This concerns, inter alia, expanding forms of participation, civil society, the public sphere and (non-profit) media outlets. The diagnosis of a supposedly growing influence of these new actors on processes of intentional social change is usually associated with the claim that any exclusive analytical focus on states and their political and legal instruments will systemically limit the possibilities of understanding the way modern society is shaped and shapes itself (Teubner 2013).

The emergence of "new" or "social" media has especially attracted high expectations with regard to the democratization of expertise, unprecedented opportunities for participation, better informed decisions and the possibility of facilitating change in ways beyond those already established institutionally (Benkler 2006; Gillmor 2006). On the one hand, governance's analytical shift toward new actors, levels and forms of interaction seems to be able to incorporate these changes rather well. On the other hand, regulation was early in accounting for "analog" forms of social pressures (Kagan 1994; Aoki and Cioffi 1999; Gunningham et al. 2004). To investigate how regulation and governance cope with aspects such as "digitalization" (Ward 1997; Emden and Midgley 2013), the contributions offer a twofold perspective.

Firstly, we may think of digitalization as something which poses new collective problems to be solved within a shaping society. Undoubtedly, the Internet and its applications constitute a crucial empirical hub for debates about novel phenomena that require novel regulatory instruments or governance arrangements. "[T]he single nation-state is hardly able to effectively regulate cross-border matters, while international treaty-making on sensitive or fast developing technical issues often fails absent consent or pace in negotiations between governments" ${ }^{2}$ In order to overcome these seeming impasses, "new forms of governing through law" have emerged. Transnational governance arrangements, such as the Internet Corporation for Assigned Names and Numbers (ICANN), bear new features that can hardly be included in classical typologies (see chapter by Viellechner). However, scrutinizing novelty in that context also shows that they deliver 
precisely on what regulation was always about - settling disputes and granting (legal) certainty.

A second stance turns the tables by asking for the shaping effects of digital media as instruments in regulation and governance. In terms of access to the public sphere, participation has certainly never been easier than in the digital age. Yet whether this technical opportunity leads to the inclusion and consideration of formerly unheard voices remains open for contestation (Edwards and McGee 2016). We risk overseeing at least two aspects when focusing on digital media's innovative features. First, traditional mass media retain their important role in shaping society and, second, new technology is neither neutral nor is it inevitably applicable in the name of the public interest (see chapters by Schrape and Mölders). As very few private sector providers create and control the digital infrastructure (and thereby also data), the possibility "to pre-format and to sanction communication more efficiently than ever before" (see chapter by Schrape) seriously mitigates hopes for innovative and more participatory forms of shaping society. The answer to such regulatory problems is currently sought in transnational arrangements (see chapter by Viellechner).

This situation might fuel expectations for social pressure or the revival of the Fourth Estate (de Burgh 2008a), even a Fourth Estate 2.0 equipped with the latest "weapons of mass persuasion" (Corman et al. 2008; Hwang 2015). Empirically, it shows that because it has never been easier to publish criticism, it is arguably also harder than ever before to actually generate impact (Mölders 2014). Social pressure stemming from the public sphere does not easily build up in modern society but requires organizational resources. In modern society, applying social pressure itself becomes an aspect of shaping, a task that organizations (have to) handle systematically (see chapter by Mölders).

Novelty serves as a vanishing point for all contributions of this volume. But what exactly does the "new" stand for when we consider "new modes of social change" in regulation and governance? In this book, two historicizing accounts shed light on the question of whether, indeed, recently observable phenomena of intentional change call for new conceptual means or whether, on the contrary, such attempts would only sell "old wines in new bottles". Of course, participation and organized attempts of public inclusion predate the digital era. While this is hardly surprising, it is striking how smoothly alleged innovative participation formats, such as consensus conferences, align with wider and older patterns of social change. The scrutiny of such procedures from the perspective of a "historical sociology of social control" sheds light on what Lutz Raphael (1996) called the "scientization of the social" since the late nineteenth century. In modern society, the public is not expected to raise its voice whenever and wherever 
it feels the need to. Rather, a new kind of expert has emerged: the social engineer who knows how to organize the public. Because the knowledge this position draws on is of predominantly social-scientific origin, it supports the diagnosis of a social-scientization of social control (see chapter by Münte). Thus, it also becomes clear that the social sciences are not only observing and trying to explain the shaping of society, but also take part in such shaping themselves. Moreover, taking the cue from the contributions of the preceding section, public pressure can certainly count as a powerful hub in processes of shaping society. However, this does not determine the direction in which this pressure works (e.g. from or toward business, the state etc.), nor what brought the public into play in first place. Do we witness an active or rather an activated public?

Activation, too, may be a misleading term, especially when we conceive of activation as an exclusively top-down type of intervention. The reconstruction of "social experiments" from the 1940s casts doubt on such assumptions. Their common core can be seen in "establishing the powers of social self-organization as scientific facts" (see chapter by Kuchenbuch). Experimenters discovered, almost by accident, that a hands-off attitude engendered self-empowering groups of participants - a process which was later described as "self-organization". Although there was no systematic plan beforehand, the results of these experiments resulted in (scientific) textbooks about participation and self-organization. This, in turn, paved the way for the hands-on manner of consultation processes which we witness (and often criticize) today and which leaves as little as possible to chance. Such historical accounts connect to, and at the same time challenge, other academic discourses on shaping society: governmentality (Foucault 1979), the shaping of the private self (Rose 1990) and the construction of the entrepreneurial self (Bröckling 2015).

By offering such wider temporal contextualization the two contributions which close the volume point to the need for empirically specific and historically sensitive research in the context of regulation and governance, especially when novelty claims are at stake. They importantly point to the fact that the "new" modes of social change we observe in contemporary societal and academic discourses are by no means marked by utter discontinuity from past eras. Speaking of novelty and intentional change in social sciences, jurisprudence and policy-making is a phenomenon that seems to be both inherent in and specific to modern society. 


\section{NOTES}

1. In addition to being a reaction to changes in the environment, such novelty claims always also reflect the altering fashions in the social sciences themselves - including, of course, turf wars about the best advertising strategies in the market of ideas.

2. In the political sciences, the concept of multilevel governance has been widely received as a fruitful approach for systematically examining the multipolar, multicontextual and empirically inevitably specific ways in which policies are designed and implemented (Hooghe and Marks 2001). 